\title{
LA PRUEBA ILÍCITA EN MATERIA LABORAL. LA REGLA DE EXCLUSIÓN MÁS AMPLIA DEL DERECHO CHILENO
}

\author{
FRANCISCO JARA BUSTOS* \\ Universidad de Chile
}

\begin{abstract}
RESUMEN: La prueba ilícita parece haber llegado para quedarse al derecho chileno desde la Reforma Procesal Penal. Sin embargo el traer a sede no criminal una institución diseñada para evitar el accionar de los agentes estatales es problemático. Esto a la luz de los derechos a la prueba y a la defensa, en procesos entre privados. La nueva justicia laboral es un caso paradigmático de esto. Se establece una regla de exclusión inédita en el derecho chileno, que extiende la prohibición a límites desconocidos por otras reglas de exclusión en nuestro ordenamiento jurídico.
\end{abstract}

Palabras clave: Prueba ilícita, derecho a la prueba, derecho a la defensa, regla de exclusión, fruto del árbol envenenado, nueva justicia laboral.

ABSTRACT: Illegal evidence is here to stay in the Chilean law since it was first introduced in the Criminal Procedure Reform. However, introducing in -non criminal- procedures a rule designed to deterrent the agents is a trouble. This, considering the right of proof, and the right to counsel, in -non criminalprocedures. The new labor justice is a paradigmatic case of that. The exclusionary rule that the Labor Code introduces is a prohibition never seen before, that extends the exclusion beyond any other rule in the Chilean legal system.

Key words: Illegal evidence, right of proof, right to counsel, exclusionary rule, fruit of the poisonouss tree, new labor justice.

\section{"Si he logrado ver más lejos ha sido porque he subido a hombros de gigantes" SIR ISAAC NEWTON}

\section{INTRODUCCIÓN ${ }^{1}$}

La Reforma a la Justicia Laboral entre sus particularidades considera la consagración de normas de exclusión probatoria ${ }^{2}$, siguiendo la tendencia de las reformas a la justicia de los últimos años.

\footnotetext{
Estudiante de Derecho de la Universidad de Chile (franciscojara1@gmail.com). Ayudante Ad honorem de las cátedras de Derecho Procesal, Derecho del Trabajo y de la Seguridad Social, Criminología y Ayudante de investigación del Centro de Derechos Humanos de la Facultad de Derecho de la Universidad de Chile.

** La idea, con otras palabras, había sido expresada antes por Bernardo de Chartres en el Siglo XII

1 En este trabajo utilizaré las siguientes abreviaturas: Código del Trabajo (CT), Código Procesal Penal (CPP), la Constitución Política de la República (CPR), y la Ley 19.968 de Tribunales de Familia (LTF). Adicionalmente haré referencias al Anteproyecto (ACPC) y al Proyecto de Código Procesal Civil (PCPC) presentado a tramitación Mensaje No 398-357 de 2009, no obstante hoy se encuentra bajo revisión por la Comisión Intraministerial, integrada por el Ministro de Justicia y destacados académicos (cuyos resultados deberíamos conocer este año). Estos documentos en: www.minjusticia.gob.cl

2 Existen problemas de mala técnica legislativa pues del texto de la norma pareciera que se trata de "no valoración", sin embargo por motivos en los que no podemos detenernos aquí, sistemáticamente debe entenderse que se trata de "reglas de exclusión”. En todo caso, no afecta en nada esta parte del argumento.
} 
La ilicitud probatoria surge como institución que busca asegurar el respeto y la eficacia de los derechos fundamentales por los agentes que detentan el ejercicio del ius puniendi, puede generar consecuencias imprevistas al ser trasladada -sin más- con estándares idénticos o incluso más exigentes a procesos entre particulares, generando problemas desde la óptica de las garantías judiciales y el derecho a la prueba.

Proteger las garantías fundamentales es una necesidad que debe considerarse. Sin embargo, el establecer limitaciones probatorias incluso más allá del resguardo de las "garantías fundamentales", como se hizo en materia del nuevo proceso laboral, genera un estándar de limitación probatoria inédito en el derecho chileno -con el subsecuente menoscabo al debido proceso- en que el legislador no pareció reparar.

Considerar la experiencia y el trabajo dogmático que está detrás de las reformas procesales que nos han precedido, tanto en Chile como en el derecho comparado, puede sernos de gran utilidad a la hora de comprender la nueva justicia laboral.

Para esto intentaremos explicar (2) por qué la prueba ilícita es un problema entre particulares de un modo que no lo es en materia procesal penal, (2.1) reflexionando sobre los límites del derecho a la prueba y (2.2) los desarrollos de la regla de exclusión. Posteriormente (3) criticaremos que en materia laboral estemos en presencia de la regla de exclusión más amplia del derecho chileno, (3.1) debido a que corresponde a la llamada "prueba ilícita en sentido amplio” y que (3.2) incluye además la llamada prueba ilícita derivada. (3.3.) Todo esto sin motivar mayores cuestionamientos dentro de la literatura iuslaboralista. (4) Posteriormente intentaremos esbozar algunos argumentos para intentar justificar la existencia de una regla tan amplia como la del artículo $453 \mathrm{~N}^{\circ} 4 \mathrm{CT}$.

(5) Terminaremos enunciando las principales conclusiones.

\section{LA PRUEBA ILÍCITA COMO PROBLEMA³}

Aunque como tal, la prueba ilícita no se encuentra nombrada como institución en la legislación nacional, desde las reformas a la justicia chilena, y en particular desde la Reforma Procesal Penal, se establecieron reglas de exclusión de prueba obtenida con vulneración de garantías fundamentales, que se encuentran inspiradas por lo que fuera el sistema de los Estados Unidos ${ }^{4}$.

Con todo, a diferencia de las discusiones que el fenómeno suscitó en materia procesal penal $^{5}$, ni el legislador nacional, ni la doctrina, ni tampoco la jurisprudencia parecen haber

\footnotetext{
3 Esta sección sigue las tesis presentes en: JARA BUSTOS, Francisco, ¿Eficacia horizontal de los derechos fundamentales? El problema del estándar de la prueba ilícita en el derecho chileno. Ponencia presentada en el V Congreso Estudiantil de Teoría Constitucional, el 19 de agosto de 2011. (En prensas).

4 Así concluye respecto de nuestro CPP en su estudio comparado ARMENTA DEU, Teresa, La prueba ilícita (Un estudio comparado). Madrid, España: Marcial Pons, 2009, pp. 43 y ss.

5 Aun cuando los principales problemas han sido de carácter interpretativo sobre la forma de actuación y las excepciones a esta regla, la exclusión de prueba por ilicitud es un tema obligatorio en la dogmática nacional. Entre los más representativos se cuentan: HeRnÁNDEZ BASUALTO, Héctor, La exclusión de la prueba ilícita en el nuevo proceso penal chileno. Santiago, Chile: Colección de investigaciones jurídicas Universidad Alberto Hurtado, 2002, passim.; HorviTZ, María Inés; LÓPEZ, Julián, Derecho Procesal Penal Chileno. Tomo II. Santiago, Chile: Editorial Jurídica de Chile, 2004, pp. 164-228; ZAPATA GARCíA, María Francisca, La Prueba Ilícita. Santiago, Chile: LexisNexis, 2004, passim.; TAVOLARI, Raúl, Instituciones en el Nuevo Pro-
} 
reparado en los problemas teóricos y prácticos que tiene el progresivo establecimiento de reglas de exclusión probatoria en procesos civiles en un sentido lato del término, es decir, en todas aquellas materias no criminales. $Y$ en efecto, se trata de algo problemático, pues supone extrapolar una regla creada para desincentivar el actuar ilegal de los órganos de persecución estatal a procesos entre particulares, cuya lógica es completamente diferente.

En materia procesal penal nos encontramos ante un caso paradigmático de "eficacia vertical" de los derechos fundamentales contra el poder punitivo del Estado. Por lo mismo, las mayores discusiones se han dado con ocasión del enjuiciamiento criminal por razones de su desarrollo histórico, donde la titularidad estatal de la persecución penal permitió el uso de medios probatorios que hoy nos parecerían lesivos de las mínimas garantías fundamentales ${ }^{6}$. Se apunta con estas medidas a limitar el accionar de quienes detentan la acción penal, proscribiéndoles actuar con racionalidad estratégica; cuestión que no pasa ni con el imputado, ni menos en materia procesal civil, donde ambas partes gozan de plenas garantías judiciales que permiten mayor grado de libertad de actuación ${ }^{7}$.

Además, desde la segunda mitad del siglo XX el reconocimiento progresivo de garantías judiciales como el debido proceso o a la defensa, ha tenido como una de sus facetas la atención a los medios de prueba en el contexto de las garantías fundamentales de la justicia civil $^{8}$. Esto puede verse en las principales constituciones occidentales y Tratados Internacionales sobre Derechos Humanos, sea regionales, como el Convenio Europeo de Derechos Humanos $(\mathrm{CEDH})$, o la Convención Americana sobre Derechos Humanos $(\mathrm{CADH})^{9}$ y en el marco del sistema de Naciones Unidas el Pacto Internacional de Derechos Civiles y el Pacto Internacional de Derechos Civiles y Políticos.

Producto de este desarrollo, el derecho a la prueba debe entenderse como garantía autónoma ${ }^{10}$ o como integrante de otra, como es el derecho a la defensa ${ }^{11}$. Su definición es

ceso Penal. Santiago, Chile: Editorial Jurídica de Chile, 2005, pp. 133-178; ECHEVERRÍA, Isabel, Los derechos Fundamentales y la Prueba Ilícita. Con especial referencia a la prueba ilícita aportada por el querellante particular y por la defensa. Santiago, Chile: Ediciones Jurídicas de Santiago, 2010, passim. Últimamente, al igual que en el derecho comparado, se han suscitado polémicas respecto al debilitamiento de la regla en pos de políticas inspiradas en la "seguridad ciudadana".

6 Roxin, Claus, Derecho procesal penal. Buenos Aires, Argentina: Editores del Puerto, 2003, pp. 563 y ss.

7 En efecto, aquí deben contrastarse los deberes que se exigen a la Fiscalía -y a los querellantes en algún sentido (como se concluye en: ECHEVERRÍA, Isabel, op. cit. (n. 5))-, y no así a los imputados a quienes se les reconocen ciertos derechos fundamentales contra la acusación penal. Del mismo modo, en materia procesal civil las reformas han entendido que el entregar poderes al juez obedece a que la sola iniciativa de los litigantes puede ser insuficiente para conducir al tribunal a la verdad sobre las afirmaciones discutidas. Al decir de Taruffo: "no se puede esperar que las partes jueguen un papel cooperativo dirigido al descubrimiento desinteresado y objetivo de la verdad", sino que tienen por objeto ganar su caso a cualquier costo "y desde luego -si es necesario- al costo de la verdad". TARUfFo, Michele, "Investigación Judicial y Producción de Prueba por las Partes", en: Revista de Derecho (Valdivia), vol. 15, 2003, pp. 205-213.

8 TARuffo, Michele, La prueba. Madrid, España: Marcial Pons, 2008, p. 56.

9 Con todo los artículos 6 . inciso $1^{\circ} \mathrm{CEDH}$, y 8 inciso $1^{\circ} \mathrm{CADH}$ que consagran garantías comunes a todo juicio son menos detalladas que aquellas referidas al proceso penal artículos 6 inciso $3^{\circ} \mathrm{CEDH}$, y 8 inciso $2^{\circ} \mathrm{CADH}$. Existe así una mayor libertad a la hora de configurar procesos civiles, siempre sobre la base de las normas de los Convenios, como se puso de manifiesto en la sentencia del Tribunal Europeo de Derechos Humanos, Dombo Beheer B. V. vs. Países Bajos. Sentencia de 17 de octubre de 1993, párrafo 32

10 Picó I JunOY, Joan, El derecho a la prueba en el proceso civil. Barcelona: J.M. Bosch Editor, 1996, p. 448.

11 FerRer Beltrán, Jordi, “Derecho a la prueba y racionalidad de las decisiones judiciales”. En: Jueces para la Democracia, p. 27. 
relativamente pacífica ${ }^{12}$, y en suma consiste "en el derecho de influir sobre el convencimiento del juez"13. De este modo debe permitirse a las partes utilizar cada medio de prueba del que dispongan en el entendido de que la verdad es una condición importante para la justicia de una resolución, y que el restringir pruebas será principalmente restricción de justicia. Por esta gran importancia, se reconoce que se trata, en suma, de una condición "del debido proceso adjetivo" de impronta constitucional ${ }^{14}$.

\subsection{LOS LÍMITES A LA PRUEBA}

El derecho a presentar todo medio de prueba para producir convicción, tiene al menos dos tipos de limitaciones, que derivan tanto del objeto de la actividad probatoria, como del respeto a ciertas formas o garantías. Entre estos se mencionan aquellos relativos a la pertinencia, relevancia o necesidad de la prueba que algunos autores identifican como "límites intrínsecos" a la actividad probatoria, y aquellos los referentes a la licitud de la prueba o "límites extrínsecos"15.

El criterio de pertinencia no plantea problemas desde la óptica del debido proceso ${ }^{16}$, sin embargo hay varias reglas de exclusión probatoria o privilegios que impiden a las partes utilizar todo el material relevante para la comprobación de sus afirmaciones sobre hechos.

Algunos de estos tienen fundamento indubitado en normas de ius cogens como es la proscripción de la tortura y de eficacia de cualquier prueba obtenida a través del tormento ${ }^{17}$. La exclusión de ese tipo de pruebas es conditio sine qua non para cualquier proceso y deben ser prohibidas, incluso si no existiesen reglas positivas en el derecho chileno sobre el tema. Ese tipo de casos "fáciles" no son el objeto de este análisis, como sí otros casos de vulneraciones menos aberrantes donde es posible balancear intereses.

De esta manera, debe existir un sano equilibrio entre los intereses que normas contraepistemológicas buscan proteger y el derecho a la prueba. Para esto una ponderación realizada seriamente puede permitir cuestionar muchas normas existentes en ordenamientos comparados, puesto que el reconocer límites de menor entidad que el resguardo del derecho a producir pruebas, equivale a limitar garantías de defensa "que tienen rango constitucional"18. Por lo mismo, la mayoría de los conflictos deberían decantarse a favor de la admisión probatoria, debiéndose encontrar "un equilibrio favorable a la admisión de to-

\footnotetext{
12 Para una definición de este derecho: PICÓ I JUNOY, JOAN. op. cit. (n. 10), pp. 18-19; TARUFFO, Michele, La prueba (n. 8), pp. 56 y ss.; CAROCCA, Alex, Garantía constitucional de la defensa procesal. Barcelona: J. M. Bosch Editor, 1998, pp. 98-99.

13 Marinoni, Luiz Guilherme; Pérez Ragone, Álvaro y Núñez Ojeda, Raúl, Fundamentos del Proceso Civil. Hacia una teoría de la adjudicación. Santiago: Abeledo-Perrot, LegalPublishing, 2010, pp. 280 y ss.

14 Ibid., p. 440.

15 Los primeros "o inherentes a la actividad probatoria, son aquellos que necesariamente deben concurrir en la prueba para que pueda considerarse como tal, y son su pertinencia y utilidad" y los segundos "se derivan del carácter procesal de este derecho, y son aquellos exigidos por las normas de proposición con carácter general" para cualquier prueba o medio probatorio. (véase: PICÓ I JUNOY, Joan, "La prueba ilícita y su control judicial en el proceso civil". En: III Congreso Panameño de Derecho Procesal, 2006, Ciudad de Panamá, Panamá, p. 160).

16 Así: TARUfFo, Michele, "Investigación Judicial y... (n. 7), p. 57.

17 Entre otros, la Convención contra la Tortura y Otros Tratos o Penas Crueles, Inhumanos o Degradantes de 1984 (artículo 15), y la Convención Interamericana para Prevenir y Sancionar la Tortura de 1985 (artículo 10).

18 Ibid.
} 
das las pruebas relevantes de que dispongan las partes" ${ }^{19}$. Solo aquellas ponderaciones dirigidas a la salvaguardia de otros intereses de especial relevancia, como "la protección de otro derecho constitucional o fundamental más importante” que, tras la debida apreciación del tribunal, permitiría sacrificar el derecho a la prueba ${ }^{20}$.

Una solución de este tipo permitiría garantizar tanto el respeto de los derechos procesales de las partes, el resguardo de ciertos intereses como secretos relevantes o la protección de otros derechos o garantías de mayor entidad, y la búsqueda de la verdad en el proceso. Del mismo modo la existencia de otros remedios y/o sanciones debería aplicarse para aquel que vulnerase determinadas garantías o derechos.

Para dilucidar mejor este debate, conviene tener en cuenta la forma en que surgió, se ha desarrollado -y está desapareciendo- la regla de exclusión en el derecho norteamericano.

\subsection{LOS DESARROLLOS DE LA JURISPRUDENCIA SOBRE EXCLUSIÓN DE LA SUPREME COURT}

Es en la jurisprudencia de la Supreme Court de los Estados Unidos desde el conocido fallo “Weeks vs. United States, 232 U.S. 383 (1914)", donde surgió la "regla de exclusión" (exclusionary rule), por la aplicación que hiciera la Corte Suprema de los derechos contenidos en la IV Enmienda (derecho a no sufrir registros ni confiscaciones irrazonables) ${ }^{21}$. Ahora, desde que surgiera esta doctrina, han existido importantes cambios jurisprudenciales.

El fundamento de restar validez a pruebas obtenidas con vulneración de garantías constitucionales es distinto al que tradicionalmente se esgrime en nuestro sistema. Para la jurisprudencia de la Supreme Court lo importante sería la disuasión, pues "tales derechos se constituyen en restricciones a la autoridad de los agentes públicos sobre los ciudadanos más que derechos individuales (deterrent efect)" 22 . De este modo, la razón que se esgrime en dicho sistema jurídico es la disuasión del actuar ilegal de los órganos de persecución criminal.

Resguardar la eficacia de los derechos y garantías entre particulares, que es la justificación más común a la introducción desmesurada de reglas sobre prueba ilícita en el derecho chileno $^{23}$ no tiene asidero alguno en el sistema que les dio vida. No obstante, la eficacia de las garantías procesales se puede ver resguardada en forma indirecta.

Prueba de lo anterior es que la exclusionary rule no entra en juego en caso de que sean particulares quienes obtienen material probatorio ilícitamente ${ }^{24}$ en materia penal, y la reticencia "a emplear la regla de exclusión cuando se trata de controversias civiles" 25.

Una tendencia minoritaria en la jurisprudencia ha hecho énfasis también en la inte-

21 Han fundamentado prohibiciones vulneraciones a la V Enmienda (derecho a no declarar contra sí mismo), la VI Enmienda (derecho a estar asistido de letrado), y la XIV Enmienda (derecho al debido proceso). ARMENTA DEU, Teresa, op. cit. (n. 4), p. 27.

23 Críticos a esto: Larroucau TORRES, Jorge, La prueba en el proceso civil. Tesis (para optar al grado de Doctor en Derecho) Santiago, Chile: Universidad de Chile, Facultad de Derecho, 2010, pp. 169 y ss.; y en el mismo sentido Jara BuSTOS, Francisco. op. cit. (n. 3), passim.

24 NúN̄EZ OJEDA, Raúl, "El Ofendido por el Delito y la Prueba en el Enjuiciamiento Criminal Español”. En: COLOMA, Rodrigo (Editor), La Prueba en el Nuevo Proceso Penal Oral. Santiago: LexisNexis, 2002. p. 118.

25 Larroucau Torres, Jorge, op. cit., (n. 23), p. 168
} 
gridad judicial (judicial integrity), basada en que el Estado no puede actuar como los delincuentes que busca castigar. Su alcance es, sin embargo, minoritario en la jurisprudencia ${ }^{26}$.

La comprensión de la regla ha variado, tanto por la comprensión de la exclusionary rule como un remedio procesal ${ }^{27}$, o en atención a que se han encontrado mejores medios para lograr el efecto disuasorio. De este modo en la última década se aprecia un declive de la exclusionary rule -"Hudson vs. Michigan 547 U.S. 586, (2006)"- basado en el mejor efecto que tendrían medidas civiles o disciplinarias para disuadir a los agentes estatales ${ }^{28}$.

En suma, podemos ver que la regla de exclusión desarrollada por la Supreme Court que hace tanto sentido en el CPP, nunca fue pensada para procedimientos entre privados, por lo que la tendencia del legislador patrio resulta poco feliz ${ }^{29}$.

\section{LA REGLA DE EXCLUSIÓN MÁS AMPLIA DEL DERECHO CHILENO}

Previo a la Reforma Procesal Laboral, aunque no existían reglas al respecto la jurisprudencia en varios casos optó por no valorar ciertas pruebas por atentar contra garantías fundamentales ${ }^{30}$. En el derecho comparado la exclusión de prueba en materia laboral tampoco es una innovación doctrinaria, e incluso en ordenamientos como el español

La afirmación puede parecer exagerada, pero no lo es. Como se ha indicado en otro lugar, si uno compara las reglas existentes de exclusión probatoria tanto en materia del Código Procesal Penal (art. 276 CPP) ${ }^{31}$, la del artículo 31 de la Ley de Tribunales de Familia $(\mathrm{LTF})^{32}$-y en algún sentido también las que se han discutido en materia de Reforma Procesal Civil en el Anteproyecto (ACPC) y el Proyecto (PCPC) ${ }^{33}-$, con aquella establecida en el

\footnotetext{
26 De hecho, la regla de exclusión en principio no opera respecto de privados, salvo si ejercer una función pública, como la seguridad privada, así: "Marsh vs. Alabama, 326 U.S. 501 (1946)".

27 “United States vs. Calandra, 414 U.S. 338 (1974)” citado por: LARroucau TORRES, Jorge, op. cit. (n. 23), p. 168.

28 En este sentido: ARMENTA DeU, Teresa, op. cit. (n. 4), p. 31.

29 Con todo, podrá retrucársenos que existen otros ordenamientos influyentes para el caso chileno como el español que han desarrollado normas de exclusión para todo tipo de procesos. Revisaremos eso en la sección (4) al intentar justificar la regla.

30 Por ejemplo las resoluciones del Octavo Juzgado de Letras del Trabajo de Santiago, Rol No 4862-2001, y el fallo de la Corte de Apelaciones de Santiago de 13.11.2006, Rol N 1954-2006. Citadas en FERRADA, Francisco, La prueba ilícita en sede civil. Tesis (para optar al grado de Magíster en Derecho). Santiago, Chile: Universidad de Chile, Facultad de Derecho, 2009 , p. 87.

31 Art. 276 inciso $3^{\circ}$ CPP. "Exclusión de pruebas para el juicio oral. (...) Del mismo modo, el juez excluirá las pruebas que provinieren de actuaciones o diligencias que hubieren sido declaradas nulas y aquellas que hubieren sido obtenidas con inobservancia de garantías fundamentales". (Las cursivas son nuestras).

32 Art. 31 LTF. "Exclusión de prueba. El juez de familia, luego de estudiar la admisibilidad de las pruebas ofrecidas, de resolver las convenciones probatorias y de escuchar a las partes que hubieren comparecido a la audiencia preparatoria, ordenará fundadamente que se excluyan de ser rendidas en el juicio aquellas que fueren manifiestamente impertinentes, tuvieren por objeto acreditar hechos públicos y notorios, resulten sobreabundantes o hayan sido obtenidas con infracción de garantias fundamentales. Las demás serán admitidas y se ordenará su rendición en la audiencia de juicio respectiva”. (Las cursivas son nuestras).

33 No obstante el proyecto definitivo aún no ha sido entregado por la Comisión Intraministerial hay buenas razones para creer que al menos en lo sustantivo el estándar se mantendrá. Las razones que nos llevan a creer esto en: JARA BUSTOS, Francisco, op. cit. (n. 3). El estándar del artículo 282 APCP y del artículo 263 PCPC es idéntico.

Art. 263 PCPC. "Exclusión de prueba. El juez, ordenará fundadamente que se excluyan de ser rendidas en el juicio aquellas pruebas que fueren manifiestamente impertinentes, tuvieren por objeto acreditar hechos públicos y notorios, resulten sobreabundantes, hayan sido obtenidas con infracción de garantias fundamentales o recaigan sobre hechos no controvertidos, a menos que se tratare de cuestiones indisponibles para las partes.

Las demás serán admitidas y se ordenará su rendición en la audiencia de juicio respectiva”.
} 
artículo $453 \mathrm{~N}^{\circ} 4$ del Código del Trabajo (CT) puede constatarse la considerable diferencia de amplitud $^{34}$.

"Art. 453 CT. En la audiencia preparatoria se aplicarán las siguientes reglas:

4) El juez resolverá fundadamente en el acto sobre la pertinencia de la prueba ofrecida por las partes, pudiendo valerse de todas aquellas reguladas en la ley.

(...)

Con todo, carecerán de valor probatorio y, en consecuencia, no podrán ser apreciadas por el tribunal las pruebas que las partes aporten y que se hubieren obtenido directa o indirectamente por medios ilícitos o a través de actos que impliquen violación de derechos fundamentales".

De este modo, es posible concluir que aunque en la legislación no existe un concepto único de exclusión probatoria, en la práctica se impone el elemento común basado en la "inobservancia de garantías fundamentales", salvo en materia laboral.

Haremos una revisión a los puntos que nos parecen más conflictivos a continuación.

\subsection{CORRESPONDE A LA PRUEBA ILÍCITA EN SENTIDO AMPLIO}

El criterio que se encuentra en el CPP, la LTF y los proyectos sobre Reforma Procesal Civil dogmáticamente se conoce como criterio restringido de prueba ilícita. Esta definición centrada en la inobservancia de garantías fundamentales prima facie nos parece la más correcta atendida la relevancia que debe asignársele al derecho a la prueba. Del otro lado, encontramos el criterio amplio, que considera en como ilícita aquella prueba contraria a una norma de derecho, con independencia de su categoría o naturaleza ${ }^{35}$.

Esto debe llamar doblemente la atención, no solo por la importancia que debiera tener el derecho a la prueba como garantía, pues de acuerdo al tenor de la disposición legal, basta que la prueba hubiese sido recabada "por medios ilícitos", sin importar la entidad de la vulneración. Podría por ejemplo vulnerarse un reglamento interno de la empresa, lo que constituiría una contravención que probablemente no afecta ningún interés tutelado constitucionalmente, o que tenga reconocimiento en tratados; sin embargo esa protección podría prevalecer sobre la búsqueda de la verdad y el debido proceso.

No se desconoce por cierto, que los procesos laborales o de familia consideran la protección de intereses relevantes y pueden justificar limitaciones probatorias más fuertes que

\footnotetext{
34 JARA BUSTOS, Francisco, op. cit. (n. 3). En la práctica las obras se refieren casi exclusivamente a la prueba obtenida con inobservancia de garantías fundamentales. HORVITZ, María Inés, LÓPEZ, Julián. op. cit. (n. 5), p. 169. Esta definición es seguida, en términos generales, en: FERRADA, Francisco. op. cit. (n. 30), p. 14.

35 Esta distinción es reconocida por Midón, Marcelo, Pruebas Ilícitas. Análisis Doctrinario y Jurisprudencial. Mendoza, Argentina: Ediciones Jurídicas de Cuyo, 2002. pp. 33 y ss. En el mismo sentido: MirAndA EsTRAMPES, Manuel, El concepto de prueba ilícita y su tratamiento en el proceso penal. Barcelona, España: J. M. Bosch Editor, 2004, pp. 22 y ss. Debe recordarse que no necesariamente todas las garantías fundamentales se encuentran en normas de la Constitución Política, por ejemplo muchas de las garantías del Título I del Libro Primero del Código Procesal penal; del mismo modo la normativa de los artículos 2 y 5 del citado cuerpo legal, o el artículo 5 CT constituyen ejemplos de garantías fundamentales establecidas en leyes, no obstante en último término son concreciones de mandatos del artículo 19 CPR, o de disposiciones de Tratados Internacionales sobre Derechos Humanos.
} 
los litigios de carácter eminentemente patrimonial ${ }^{36}$, sin embargo el criterio de exclusión debe ser menor que las prohibiciones existentes en materia penal.

La gravedad de esto se vislumbra al constatar que el Estado no detenta ningún derecho constitucional para poder producir evidencias, y sin embargo la prueba derivada de actuaciones declaradas nulas hoy es plenamente admisible gracias a la Ley $\mathrm{N}^{\circ} 20.253$, también llamada Agenda Corta Antidelincuencia. Vulnerar la legalidad no es ya óbice para la persecución penal que puede privar a alguien de su libertad o sus bienes, y sin embargo en materia laboral vulneraciones a la legalidad o a normas de menor rango pueden suscitar la inutilizabilidad de las evidencias.

\subsection{COMPRENDERÍA TAMBIÉN LA EXCLUSIÓN DE PRUEBA ILÍCITA DERIVADA}

La pregunta por la prueba ilícita derivada surgió casi desde que existe la exclusionary rule. Para estos efectos fue acuñada la "doctrina del fruto del árbol envenenado" (fruit of the poisonouss tree), o doctrina de los efectos reflejos de la prueba ilícita, que en buenas cuentas extiende el ámbito de acción de la exclusión a aquellas pruebas obtenidas a consecuencia de una infracción a derechos fundamentales. Esta doctrina se desarrolló desde "Silverthorne Lumber Co vs. United States, 251 U.S. 385, (1920)", donde "se decidió que no se podía intimar a una persona para que entregara documentación a cuyo conocimiento había llegado la policía a través de una allanamiento ilegal" 37.

La expresión fue acuñada en "Nardone vs. United States, 308, U.S. 383 (1939)" donde la Supreme Court señaló:

"Una vez que está establecido -como lo ha sido plenamente aquí- el juez del caso debe dar oportunidad; por mucho que sea estrechamente restringida, al acusado para probar que una parte substancial del caso seguido en su contra ha sido fruto del árbol venenoso". Esto deja amplia oportunidad al Gobierno para convencer a la Corte que la prueba tuvo un origen independiente" 38 .

Sin embargo, en la misma cita se reconocen excepciones, como el origen independiente de la prueba, pues la exclusión apunta al modo de obtención. Entender otra cosa implicaría volver intangibles ciertas evidencias cerrando toda posibilidad a lograrlas por las vías que la ley autorice.

Otras atenuaciones a esta doctrina se fueron reconociendo paulatinamente, aunque algunas obedecen más bien a orientaciones de política criminal y admiten cuestionamien$\operatorname{tos}^{39}$. Entre estas podemos nombrar: la "doctrina de la fuente independiente" en la sentencia "Murray vs. United States, 487 U.S. 533 (1988)", la "regla del descubrimiento inevitable" con "Nix vs. Williams, 467 U.S. 431 (1984)", el "principio del vínculo atenuado" con

\footnotetext{
36 Sobre esto JANA, Andrés, La eficacia horizontal de los derechos fundamentales. [En línea] <http://islandia.law.yale.edu/sela/ sjana.pdf> [consulta: 08 abril 2011].

37 Zapata García, María Francisca, op. cit. (n. 5), p. 28.

38 Traducción propuesta por Ibid., p. 29.

39 Ibid. p. 31.
} 
"Nardone vs. United States, 308 U.S. 338 (1939)", la "excepción de buena fe del agente" que se expresa en "United States vs. Leon, 468 U.S. 897 (1984)" 40.

En nuestro país, en materia procesal penal se admite favorablemente la idea de que la exclusión de prueba ilícita derivada por la vía del descubrimiento inevitable, aun con falta de texto expreso del $\mathrm{CPP}^{41}$. Sin embargo, no es la única posición doctrinaria ni jurisprudencial. En materia procesal laboral la disposición que reglamenta la exclusión del medio "obtenido directa o indirectamente" se trata de una institución inédita cuyos alcances jurisprudenciales y amplitud o restricción interpretativa restan por conocerse.

\subsection{EXISTE ESCASO ANÁLISIS CRÍTICO DE LA NORMA A LA LUZ DEL DERECHO A LA DEFENSA}

Con todo, en la literatura nacional dedicada a la justicia laboral estas preocupaciones sobre la relevancia del derecho a prueba parecen ser inexistentes a la hora de analizar la norma del artículo 453 CT. De esta manera podemos ver que mayoritariamente el análisis de la disposición legal no repara en el punto ni se pronuncia a favor o en contra de la regla ${ }^{42}$, o bien la incorporación de prohibiciones probatorias es recibida positivamente ${ }^{43}$. Excepcionalmente el profesor Christian Melis se refiere a la tensión entre el respeto a los derechos fundamentales y la averiguación de la verdad, respecto de la proporcionalidad del medio empleado, como parámetro de admisibilidad ${ }^{44}$.

Existen por cierto obras dogmáticas, tesis y artículos que se refieren al derecho a la prueba y/o los problemas sistemáticos de la prueba ilícita en nuestro país ${ }^{45}$, sin embargo como anteriormente se ha advertido, existe un grave problema de coherencia en la forma de entender el derecho procesal civil ${ }^{46}$ y hay escaso o nulo diálogo entre subsistemas que tienen más en común de lo que se cree y que debieran tener por fin el permitir un "acceso igualitario a la justicia a toda la sociedad" 47 .

\footnotetext{
40 Ibid. pp. 151-154 (vínculo atenuado), pp. 207-211 (buena fe del agente y descubrimiento inevitable).

41 Hernández Basualto, Héctor, op. cit. (. 5), pp. 81 y ss.; Horvitz, María Inés, LÓpez, Julián, op. cit. (n. 5), pp. 221 y ss.; ZaPATA GARCÍA, María Francisca, op. cit. (n. 5), pp. 32 y ss.; TAVOlari, Raúl, op. cit. (n. 5), pp. 141 y ss.

42 Corporación Administrativa Del Poder Judicial. Manual de Estudio Juzgados de Letras del Trabajo. Santiago, Chile, 2007. p. 88.; SIlva MONTES, Rodrigo. Manual de procedimiento laboral. Santiago, Chile: Editorial Jurídica de Chile, 2009, p. 37; ORELlANA, Fernando, Comentarios al nuevo proceso laboral. Tercera Edición. Santiago, Chile: Librotecnia, 2009, pp. 188-189.

43 Tapia Guerrero, Francisco (dir.), Manual de Juicio del Trabajo. Santiago, Chile: Academia Judicial, 2008, pp. 98 y ss.; WALTER, Rodolfo y LANATA, Gabriela, Régimen legal del nuevo proceso laboral chileno. Sexta Edición. Santiago, Chile: LegalPublishing, 2009, pp. 207-208; CABEZAS PINO, René, Aspectos relevantes de la prueba en el nuevo proceso laboral Tesis (para optar al grado de licenciado en Ciencias Jurídicas y Sociales). Santiago, Chile, Universidad de Chile, Facultad de Derecho, 2010, pp. 77 y ss.; FERNÁNDeZ TOledo, Raúl, Las facultades y deberes del juez en materia probatoria en el proceso laboral. Santiago, Chile: PuntoLexThomson Reuters, 2011, pp. 272 y ss.; FERRADA, Francisco. op. cit. (. 30), pp. 162 y ss. (El autor no obstante hubiera esperado un "homenaje mejor logrado en esta sede" (Ibid., p. 165). Sin embargo sus críticas no apuntan a la extensión de la regla ni a la afectación de garantías procesales, sino a la situación previa a la reforma donde existía exclusión por vía jurisprudencial.

44 Melis VALENCIA, Christian, Los derechos fundamentales de los trabajadores como límites a los poderes empresariales. Santiago: Abeledo-Perrot, LegalPublishing, 2009, pp. 79-80.

45 Larroucau Torres, Jorge. op. cit. (n. 23), pp. 163 y ss.; Marinoni, Luiz Guilherme, Pérez Ragone, Álvaro, NúÑEZ OJEDA, Raúl, op. cit. (n. 13), extensamente en el Capítulo III "La Defensa en el Estado Constitucional".

46 Siguiendo a Taruffo: JARA BUSTOS, Francisco, "La facilidad probatoria en el procedimiento de tutela laboral. Constitucionalidad y tramitación procesal”, en: Revista Chilena de Derecho del Trabajo y de la Seguridad Social, vol. 1 No 2, pp. 153-184. Santiago, Chile: Departamento de Derecho del Trabajo y de la Seguridad Social, Facultad de Derecho, Universidad de Chile, 2010, p. 157.

47 Ibid.
} 


\section{ARGUMENTOS QUE PODRÍAN JUSTIFICAR LA AMPLITUD DE LA REGLA DEL ARTÍCULO $453 \mathrm{~N}^{\circ} 4 \mathrm{CT}^{48}$}

Es importante, con todo, evitar caer en falacias como la del "muñeco de paja" e intentar dar a conocer argumentos a favor de este artículo, que salgan de los lugares comunes del neoconstitucionalismo que permite casi cualquier argumentación. Por lo mismo sienta bases febles para el debate, pues no permite razonar un estándar, dado que tanto el artículo 31 LTF y el artículo $453 \mathrm{~N}^{\circ} 4 \mathrm{CT}$ protegen igualmente derechos fundamentales.

Por lo mismo hemos intentado buscar argumentos para apoyar la existencia de una prohibición de esta amplitud, en el entendido de que si en la literatura esta no ha sido justificada puede no deberse tanto a que no existan argumentos, como al hecho de que nadie haya criticado una norma -en apariencia- tan buena y necesaria.

\subsection{CARÁCTER TUITIVO DEL ORDENAMIENTO LABORAL}

El primero de estos es el conocido carácter tutelar del derecho del trabajo, y entre otras normas el artículo $5 \mathrm{CT}$ que enfatiza el deber de respeto a las garantías fundamentales del trabajador, considerando tanto la protección de los derechos constitucionales laborales, como los inespecíficos cuyo respeto configuraría la llamada "ciudadanía en la empresa" ${ }^{49}$.

Es un hecho que sería injusto desconocer, que el Derecho del Trabajo por esta especial característica ha sido pionero en el ámbito de la reflexión de los derechos fundamentales entre particulares $s^{50}$ y también lo ha sido en materia de ilicitud probatoria en importantes ordenamientos comparados $^{51}$. Por ejemplo en el derecho español -señala Jequier- el proceso penal no monopoliza las reflexiones sobre prueba ilícita y una prueba de ello "es que el primer pronunciamiento del Tribunal Constitucional español -TC- sobre esta cuestión fue en relación con un asunto incardinado en un proceso laboral y no penal" 52 .

Ahora, aun cuando se trata de un argumento a considerar, sistemáticamente parece problemático, dado que el carácter protector no es privativo de las relaciones laborales, sino también en el derecho de familia, y en particular se ve reflejado en los principios de la LTF. Del mismo modo, ante la constatación empírica de que la desigualdad en ciertas áreas del ordenamiento jurídico, como en el derecho del consumidor, la solución tampoco ha sido generar un estándar tan alto de prohibiciones probatorias.

Se violenta así, la igualdad ante la ley al establecer estándares tan disímiles de aceptación de prueba.

\footnotetext{
48 Estos argumentos han sido esbozados en: JARA BUSTOS, Francisco, ¿Eficacia horizontal de... (n. 2); sin embargo para efectos de este trabajo estos han sido más desarrollados.

49 Gamonal, Sergio, El Procedimiento de Tutela de Derechos Laborales. Santiago, Chile: LegalPublishing, 2008, pp. 7 y ss.

50 JANA, Andrés, op. cit. (n. 36), p. 7. El autor destaca que una cosa análoga ha ocurrido en el derecho de familia.

51 La influencia del Derecho español, en especial de la Ley de Enjuiciamiento Civil de 2000 y la Ley de Procedimiento Laboral de 1994, es notoria, sobre todo en las normas sobre prueba del nuevo proceso de tutela laboral, remito a: JARA BUSTOS, Francisco, "La facilidad probatoria... (n. 46), p. 170.

52 Jequier, Eduardo, "La obtención ilícita de la fuente de la prueba en el proceso civil. Análisis comparativo del ordenamiento jurídico español y chileno”, en: Revista Chilena de Derecho, vol. 34 N 3, 457-494, diciembre 2007, p. 460.
} 


\subsection{EVITA DISCUSIONES SOBRE PROCEDENCIA DE PRUEBA ILÍCITA DERIVADA}

Este argumento alude a que permitiría evitar discusiones doctrinarias como las del derecho comparado sobre la extensión de las reglas sobre proscripción de la prueba ilícita, en particular sobre la eficacia de la prueba derivada.

$\mathrm{Al}$ revisar las teorías norteamericanas de exclusión de la prueba (y de limitación a la regla de exclusión), podemos ver que esta regla puede constituir una forma de terciar el debate. No faltan voces que aseguran que nuestro ordenamiento jurídico ha recepcionado con esta norma la "doctrina de los frutos del árbol envenenado" en su versión procesal laboral53. Esto se asemeja a lo que sería el artículo 11 inciso $1^{\circ}$ de la Ley Orgánica del Poder Judicial (LOPJ) español, que con todo es menos amplio que la norma procesal laboral.

"Art. 11.1 LOPJ: En todo tipo de procedimiento se respetarán las reglas de la buena fe. No surtirán efectos las pruebas obtenidas, directa o indirectamente, violentando los derechos o libertades fundamentales".

En este sentido René Cabezas Pino celebra que esta regla permitiría "evitar la discusión doctrinaria sobre la extensión de la regla de exclusión de la prueba derivada de un ilícito, proporcionando una solución legal, sin que exista necesidad de una salida jurisprudencial a la controversia como ocurrió en muchos países" 54 .

Como crítica, sin embargo, puede mencionarse que los jueces igualmente podrían modular estas reglas, o darles excepciones, como las que ha encontrado la teoría de los frutos del árbol envenenado en el derecho norteamericano. Claro -podrá respondérsenos-, que existe una diferencia entre la exclusión jurisprudencial y el artículo 11 inciso $1^{\circ}$ LOPJ, y es que la segunda es una norma escrita de tenor aparentemente inequívoco, pero no ha impedido que en el derecho español existan diferentes lecturas sobre el tenor de la norma.

Un sector mayoritario de la doctrina y la jurisprudencia española entienden que en su sistema jurídico se acoge la "teoría de los frutos del árbol envenenado" 55 , sin embargo otros autores como Joan Picó I Junoy han sostenido apoyándose en lo argumentado en el fallo del Tribunal Constitucional español que motivó la creación del precepto legal, que la expresión directa:

"alude a la ineficacia de todo elemento probatorio para cuya obtención se haya infringido directamente un derecho fundamental (ejemplo, la inviolabilidad del domicilio o la integridad física o psíquica de las personas), así como también la ineficacia del medio de prueba a través del cual se intenta dar entrada en el proceso a dicho elemento probatorio, ya que ello supone indirectamente conculcar otros derechos fundamentales (así, los referentes al proceso con todas las garantías y la igualdad de las partes" 56 .

\footnotetext{
53 Así lo ha entendido Cabezas Pino, René, op. cit. (n. 43), pp. 82-83.; Melis VAlenCia, Christian, op. cit. (n. 44), p. 81.

54 Cabezas Pino, René, op. cit. (n. 43), p. 85.

55 Miranda Estrampes, Manuel, op. cit. (n. 35), pp. 27-28.

56 Picó I JunOY, Joan, “La prueba ilícita... (n.15), pp. 167-168.
} 
Además, complementa el autor que "la doctrina de los frutos del árbol prohibido supone un límite a la eficacia y virtualidad del derecho a la prueba, configurado como fundamental en nuestra norma normarum (artículo 24 inciso $2^{\circ}$ C.E.) lo que obliga, como reiteradamente destaca el tribunal constitucional, a efectuar una lectura restrictiva del mismo" 57 . Por estos motivos, para el autor las disposiciones del citado cuerpo legal no suponen la consagración de la doctrina del efecto reflejo de la prueba ilícita.

Lo que interesa destacar aquí es que ni la fórmula norteamericana, ni española han impedido que existan debates sobre la certeza de admisión de pruebas ilícitas, y sospechamos que la norma del artículo 453 CT tampoco debería hacerlo atendiendo la multiplicidad de intereses en juego, los cuales deben ser ponderados por el magistrado a la hora de admitir o no un determinado medio de prueba.

\subsection{RESPONDERÍA A UNA MANIFESTACIÓN DEL PRINCIPIO DE BUENA FE PROCESAL}

Este principio se establece en el nuevo artículo 425 CT. La buena fe procesal, en pocas palabras, supone considerar que el proceso aunque es una disputa de intereses, no puede utilizar cualquier medio para lograr un resultado. Y claro, que aun cuando la opción de entregar potestades probatorias al juez deriva del hecho -harto obvio- de que resultaría complejo establecer como regla general un deber de colaboración de aportar pruebas, razón por la que esta facultad se entrega al imparcial, la idea de buena fe si podría explicar la existencia de ciertos principios de facilidad probatoria.

En esa línea se ha insinuado que "si no se está de acuerdo con estas concepciones de una lucha leal -que permitirían justificar las cargas probatorias dinámicas- dejaría de tener sentido la idea de exclusión de la prueba ilícita” 58 .

Más directamente Pablo Cifuentes ha sindicado a la norma de prueba ilícita como manifestación normativa de la buena fe. Adicionalmente para el autor, esta norma "no provoca mayores dificultades respecto de su legitimidad, por cuanto se limita a desincentivar la producción y adquisición de medios probatorios por vías ilícitas, que constituyen conductas positivas de mala fe" 59 .

Este nos parece uno de los argumentos más sostenibles. Sin embargo, podríamos criticarlo si pensamos que la buena fe procesal, por mucho que puede ser un argumento que apoya la exclusión probatoria - pues su fundamento último son las garantías fundamentales-, no explicaría a cabalidad la exclusión probatoria, y de aprobarse disposiciones sobre buena fe procesal en el Nuevo Código Procesal Civil, como muy seguramente ocurrirá, y las normas de exclusión probatoria de la nueva legislación procesal civil se mantienen en una noción de "prueba ilícita restringida", estaríamos en presencia de otro problema de coherencia. Revisa Chilena de Derecho del Trabajo y de la Seguridad Social, vol. 1 No 2, pp. 91-108. Santiago, Chile: Departamento de Derecho del Trabajo y de la Seguridad Social, Facultad de Derecho, Universidad de Chile, 2010, pp. 99. Con todo, discrepo de otras afirmaciones de ese artículo.
} 


\subsection{LA JUSTIFICACIÓN DE ESTA REGLA PUEDE ESTAR EN LAS DISCUSIONES DEL FORO PARA LA REFORMA O EN LA DISCUSIÓN PARLAMENTARIA \\ El inusual diseño de la regla del CT, podría deberse a la deliberación del parlamento,} o bien estar motivada por las reflexiones de los académicos y abogados que formaron parte del Foro que estudió la Reforma a la Justicia Laboral.

Lamentablemente nos vemos de nuevo enfrentados a un camino sin salida. El "Mensaje $\mathrm{N}^{\circ}$ 4-350" contiene una referencia al particular al expresar, sobre los medios de prueba, que "de manera novedosa, se incorpora en el proyecto una regla dirigida a privar de valor probatorio a las pruebas que las partes aporten y que se hubieren obtenido directa o indirectamente por medios ilícitos o a través de actos que impliquen violación de derechos fundamentales" ${ }^{\prime 6}$. La norma original del proyecto, el artículo 458 inciso $4^{\circ}$ CT que consagra la misma regla de exclusión del actual $453 \mathrm{CT}^{61}$, fue aprobada en el Primer Informe de la Comisión de Trabajo por unanimidad ${ }^{62}$.

La única modificación sustantiva que se sugirió se encuentra en el Primer Boletín de Indicaciones del Senado, donde en la indicación 122, el senador Boeninger propuso eliminar la frase final "o a través de actos que impliquen violación de derechos fundamentales"63. Es decir, habría reducido la norma a una extraña prohibición de prueba ilegal, y prueba indirectamente obtenida de prueba ilegal (que habría configurado también una figura sui generis).

No cabe ahora elucubrar si esta recomendación obedecía a algún cuestionamiento del senador Boeninger hacia los problemas interpretativos derivados de los derechos fundamentales, a una mentalidad autoritaria, o bien, a alguna adscripción teórica poco conocida, toda vez que la moción rechazada en el Segundo Informe de la Comisión de Trabajo ${ }^{64}$. De ahí la tramitación avanzó hasta derivar en el texto que vio la luz en el art. $453 \mathrm{~N}^{\circ} 5$ inciso $3^{\circ}$.

Su actual numeración se debe a la llamada "reforma de la reforma", donde la regla no fue objeto de discusión y pasó a la ubicación que conocemos del artículo 453 No $4^{65}$.

Descartado el Congreso Nacional, donde la norma, tal como las disposiciones que gobiernan la prueba ilícita en otras reformas ha sido un tópico que a la legislatura parece no llamarle la atención, la mirada debería posarse sobre el Foro que inspiró la Reforma. Con todo, esto no será de gran ayuda y la filiación intelectual de la norma en el proyecto presidencial seguirá siendo un misterio, ya que ni siquiera el Foro para la Reforma a la Justicia Laboral y Previsional ${ }^{66}$ contemplaba una idea de exclusión tan amplia, sino que se centraban en la definición de prueba ilícita restringida, con visos de la "teoría del fruto del árbol envenenado"67.

\footnotetext{
60 Historia de la Ley No 20.087. Biblioteca del Congreso Nacional. 3 de enero de 2006. Disponible en <www.bcn.cl>. p. 18.

61 Ibid., pp. 37-38.

62 Ibid., p. 103.

63 Ibid., p. 492

64 Ibid., p. 600

65 Historia de la Ley No 20.260. Biblioteca del Congreso Nacional. 29 de marzo de 2008. Disponible en <www.bcn.cl>, p. 84 .

66 Esta entidad, integrada por personalidades de distintas esferas vinculadas al Derecho del Trabajo diseñó una propuesta de reforma. En 2002 se entregó al Ministerio de Justicia el documento "Bases Fundamentales para la Reforma de la Justicia Laboral y Previsional que, a su turno, debería servir de base del proyecto de reforma. Consúltese: WALTER, Rodolfo y LANATA, Gabriela. op. cit. (n. 43), pp. 24 y ss.

67 Dentro del apartado 2.1 Letra C, podemos encontrar: "En materia de medios de prueba, debe autorizarse a las partes
} 


\section{COMENTARIOS FINALES Y CONCLUSIONES}

En estas reflexiones hemos intentado plasmar algunas de nuestras preocupaciones por un tópico, que como hemos demostrado, no ha sido objeto de gran preocupación ni para el Parlamento, ni para la dogmática iuslaboralista. Como resumen de las mismas enumeramos las siguientes:

1) Deben tomarse en cuenta los desarrollos y discusiones que se han dado en el derecho chileno y comparado respecto de otras normas sobre ilicitud probatoria para poder comprender que existe una problemática con esta figura en el CT.

2) El problema se suscita porque, a diferencia de lo que sucede en materia penal, en todo ámbito no criminal las partes detentan ciertos derechos fundamentales al debido proceso, que no detentan los órganos de persecución criminal.

3) Prima facie, la vulneración de derechos fundamentales como límite a la prueba ilícita parece el más atendible, considerando que existe cierta proporcionalidad entre ambos intereses.

4 No obstante lo anterior, en el derecho norteamericano la regla de exclusión va en retroceso por aplicación de sanciones civiles y criminales.

5 La regla de exclusión laboral es, con mucho, la regla de exclusión más amplia del derecho chileno, lo que debería preocuparnos atendido a que mientras el Ministerio Público incrementa sus facultades, los particulares tienen mayores restricciones, lo que debería preocupar a cualquiera en una sociedad libre.

6) A nuestro juicio son mejores los argumentos que recomendarían modificar la regla, que aquellos que señalan las ventajas de la misma y su justificación.

Con todo, las mayores reflexiones deberán hacerse en algún tiempo más cuando nuestros tribunales decidan sus criterios y se vea cómo han sido interpretadas estas normas. La forma como operen los principios particulares del Derecho del Trabajo, el desarrollo de garantías como el derecho a la defensa, la pregunta por cómo influirá a futuro la Reforma Procesal Civil -de concretarse- como ordenamiento supletorio, y también la necesidad del establecer parámetros claros para que los empleadores sepan que se puede hacer y no hacer. Seguramente de responderse estas cuestiones será en instancias de nulidad, considerando que el momento para que opere la regla exclusión es la audiencia preparatoria

Esperamos haber contribuido al debate.

para valerse de cuantos medios de prueba se encuentren regulados en la ley, admitiéndose como tales los medios mecánicos de reproducción de la palabra, de la imagen y del sonido, salvo que se hubieran obtenido, directa o indirectamente, mediante procedimientos que supongan violación de derechos fundamentales y libertades públicas" ( las cursivas son nuestras). Bases Fundamentales para la Reforma de la Justicia Laboral y Previsional. Disponible en <www.cejamericas.org>, p. 32. 


\section{BIBLIOGRAFÍA}

ARMENTA DeU, Teresa. La prueba ilícita (Un estudio comparado). Madrid, España: Marcial Pons, 2009.

Cabezas Pino, René. Aspectos relevantes de la prueba en el nuevo proceso laboral. Tesis (para optar al grado de licenciado en Ciencias Jurídicas y Sociales). Santiago, Chile: Universidad de Chile, Facultad de Derecho, 2010

CAROCCA, Alex. Garantía constitucional de la defensa procesal. Barcelona: J. M. Bosch Editor, 1998.

CARocca, Alex. "Una primera aproximación al Tema de la Prueba Ilícita en Chile”, en: Ius et Praxis, vol. 4, N 2, pp. 301-322. Talca: Facultad de Ciencias Jurídicas y Sociales, Universidad de Talca, 1998.

Cifuentes, Pablo. "El deber de buena fe en los procedimientos laborales: noción, manifestación y problemática”, en: Revisa Chilena de Derecho del Trabajo y de la Seguridad Social, vol. 1 N² 2, pp. 91 - 108. Santiago, Chile: Departamento de Derecho del Trabajo y de la Seguridad Social, Facultad de Derecho, Universidad de Chile, 2010.

Corporación Administrativa del POder Judicial. Manual de Estudio Juzgados de Letras del Trabajo. Santiago, Chile, 2007.

ECHEVERRÍA, Isabel. Los derechos Fundamentales y la Prueba Ilícita. Con especial referencia a la prueba ilícita aportada por el querellante particular y por la defensa. Santiago, Chile: Ediciones Jurídicas de Santiago, 2010.

FERNÁNDEZ TOLEDO, Raúl. Las facultades y deberes del juez en materia probatoria en el proceso laboral. Santiago, Chile: PuntoLex-Thomson Reuters, 2011.

FERradA, Francisco. La prueba ilícita en sede civil. Tesis (para optar al grado de Magíster en Derecho) Santiago, Chile: Universidad de Chile, Facultad de Derecho, 2009.

FERRER Beltrán, Jordi. "Derecho a la prueba y racionalidad de las decisiones judiciales”, en: Jueces para la Democracia, $\mathrm{N}^{\circ}$ 47, pp. 27-34, 2003.

Gamonal, Sergio. El Procedimiento de Tutela de Derechos Laborales. Santiago, Chile: LegalPublishing, 2008.

HERNÁNDEZ BASUALTO, Héctor. La exclusión de la prueba ilícita en el nuevo proceso penal chileno. Santiago, Chile: Colección de investigaciones jurídicas Universidad Alberto Hurtado, 2002.

Horvitz, María Inés; López, Julián. Derecho Procesal Penal Chileno. Tomo II. Santiago, Chile: Editorial Jurídica de Chile, 2004.

JANA, Andrés. La eficacia horizontal de los derechos fundamentales. [En línea] http://islandia.law.yale.edu/sela/ sjana.pdf

JARA BUSTOS, Francisco. "La facilidad probatoria en el procedimiento de tutela laboral. Constitucionalidad y tramitación procesal”, en: Revisa Chilena de Derecho del Trabajo y de la Seguridad Social, vol. $1 \mathrm{~N}^{\circ}$ 2, pp. 153-184. Santiago, Chile: Departamento de Derecho del Trabajo y de la Seguridad Social, Facultad de Derecho, Universidad de Chile, 2010.

JARA Bustos, Francisco. ¿Eficacia horizontal de los derechos fundamentales? El problema del estándar de la prueba ilícita en el derecho chileno. Ponencia presentada en el V Congreso Estudiantil de Teoría Constitucional, 19 de agosto de 2011.

JEQUIER, Eduardo. "La obtención ilícita de la fuente de la prueba en el proceso civil. Análisis comparativo del ordenamiento jurídico español y chileno", en: Revista Chilena de Derecho, vol. 34 N³, 457-494, diciembre. Santiago, 2007.

LARroucau Torres, Jorge. La prueba en el proceso civil. Tesis (para optar al grado de Doctor en Derecho) Santiago, Chile: Universidad de Chile, Facultad de Derecho, 2010.

Marinoni, Luiz Guilherme; Pérez Ragone, Álvaro; NúÑEz OjedA, Raúl. Fundamentos del Proceso Civil. Hacia una teoría de la adjudicación. Santiago: Abeledo-Perrot, LegalPublishing, 2010 
MELIS VALENCIA, Christian. Los derechos fundamentales de los trabajadores como limites a los poderes empresariales. Santiago: Abeledo-Perrot, LegalPublishing, 2009.

Midón, Marcelo. Pruebas Ilícitas. Análisis Doctrinario y Jurisprudencial. Mendoza, Argentina: Ediciones Jurídicas de Cuyo, 2002.

Miranda ESTRAMPES, Manuel. El concepto de prueba ilícita y su tratamiento en el proceso penal. Barcelona, Espaก๊a: J. M. Bosch Editor, 2004.

NúÑEz OJEDA, Raúl. "El Ofendido por el Delito y la Prueba en el Enjuiciamiento Criminal Español”. En: CoLOMA, Rodrigo (Editor). La Prueba en el Nuevo Proceso Penal Oral. Santiago: LexisNexis, 2002.

Orellana, Fernando. Comentarios al nuevo proceso laboral. Tercera Edición. Santiago, Chile: Librotecnia, 2009.

PICÓ I JUNOY, Joan. El derecho a la prueba en el proceso civil. Barcelona: J.M. Bosch Editor, 1996.

PICÓ I JunOY, Joan. "La prueba ilícita y su control judicial en el proceso civil”. En: III Congreso Panameño de Derecho Procesal. Panamá: Ciudad de Panamá, 2006.

RoXIn, Claus. Derecho procesal penal. Buenos Aires, Argentina: Editores del Puerto, 2003.

Silva Montes, Rodrigo. Manual de procedimiento laboral. Santiago, Chile: Editorial Jurídica de Chile, 2009.

TARUffo, Michele. “Investigación Judicial y Producción de Prueba por las Partes”, en: Revista de Derecho (Valdivia), vol. 15, pp. 205-213. Valdivia, Chile, 2003.

TARUfFo, Michele. La prueba. Madrid, España: Marcial Pons, 2008.

Tapia Guerrero, Francisco (dir.). Manual de Juicio del Trabajo. Santiago, Chile: Academia Judicial, 2008.

Tavolari, Raúl. Instituciones en el Nuevo Proceso Penal. Santiago, Chile: Editorial Jurídica de Chile, 2005.

WALter, Rodolfo y LANATA, Gabriela. Régimen legal del nuevo proceso laboral chileno. Sexta Edición. Santiago, Chile: LegalPublishing, 2009.

Zapata García, María Francisca. La Prueba Ilícita. Santiago, Chile: LexisNexis, 2004. 